\title{
Electron-deficient pyridinium salts/thiourea cooperative catalyzed $O$-glycosylation via activation of $O$-glycosyl trichloroacetimidate donors
}

\author{
Mukta Shaw ${ }^{1}$, Yogesh Kumar ${ }^{1}$, Rima Thakur ${ }^{2}$ and Amit Kumar ${ }^{* 1}$
}

\author{
Full Research Paper \\ Address: \\ ${ }^{1}$ Department of Chemistry, Indian Institute of Technology Patna, Bihta \\ 801106, Bihar, India and ${ }^{2}$ Department of Chemistry, National Institute \\ of Technology Patna, Patna 800005, Bihar, India \\ Email: \\ Amit Kumar ${ }^{*}$ - amitkt@iitp.ac.in \\ * Corresponding author \\ Keywords: \\ cooperative catalysis; electron-deficient pyridinium salts; O-glycoside; \\ regioselectivity; thiourea
}

\author{
Beilstein J. Org. Chem. 2017, 13, 2385-2395. \\ doi:10.3762/bjoc.13.236 \\ Received: 27 July 2017 \\ Accepted: 04 October 2017 \\ Published: 09 November 2017 \\ Associate Editor: S. Flitsch \\ (C) 2017 Shaw et al.; licensee Beilstein-Institut. \\ License and terms: see end of document.
}

\begin{abstract}
The glycosylation of $O$-glycosyl trichloroacetimidate donors using a synergistic catalytic system of electron-deficient pyridinium salts/aryl thiourea derivatives at room temperature is demonstrated. The acidity of the adduct formed by the 1,2-addition of alcohol to the electron-deficient pyridinium salt is increased in the presence of an aryl thiourea derivative as an hydrogen-bonding cocatalyst. This transformation occurs under mild reaction conditions with a wide range of $O$-glycosyl trichloroacetimidate donors and glycosyl acceptors to afford the corresponding $O$-glycosides in moderate to good yields with predictable selectivity. In addition, the optimized method is also utilized for the regioselective $O$-glycosylation by using a partially protected acceptor.
\end{abstract}

\section{Introduction}

The glycosidic linkage is the principal bond present in a crucial class of biomolecules such as oligosaccharides and glycoconjugates, where one sugar unit is linked with another sugar unit or any other molecules (aglycons) [1-4]. Owing to their high importance, several efficient protocols have been developed for the stereoselective glycosylation in the past few decades [5-10] However, the synthesis of fundamental glycosidic bonds with high efficiency and selectivity yet remains one of the major challenges for organic chemists, in particular, carbohydrate chemists.
Nature extensively employs small organic molecules as catalysts for the acceleration of many important biochemical reactions, such as glycosyltransferase reactions, hydrolysis of strong amide bonds and others [11-13]. Taking inspiration from nature, in the last few decades chemists around the world have utilized organic molecules to accelerate many imperative organic transformations [14-17]. One of the major applications of organocatalysis lies in the field of enantioselective synthesis, where organocatalysts are considered as fundamental tools in the catalysis toolbox [18-22]. Moreover, the reactivity and 
selectivity of organocatalysts can be further amplified in the presence of other cocatalysts known as "cooperative catalysis" [23]. In particular, cooperativity between Brønsted acids and hydrogen-bonding cocatalysts such as thiourea derivatives has attracted much interest [24-29]. Despite the broad application of cooperative catalysis, it is still uncommonly employed in the area of carbohydrate chemistry, especially for glycosylation reactions, due to the prerequisite of having both catalysts being compatible under the reaction conditions. The Schmidt group has successfully applied the synergistic catalysts (thiourea derivatives with phosphorus acids) for stereoselective $O$-glycoside bond formation [30]. Similarly, Galan et al. reported a method for the preparation of 2-deoxyglycosides from glycals under the influence of cooperative catalysis (chiral phosphoric acids/thiourea derivatives) [31]. Encouraged by these reports and our own research interest in developing stereoselective glycosylation methods, we decided to focus our attention on the synthesis of glycosides via cooperative catalysis. A highly reactive glycosyl donor for instance, $O$-glycosyl trichloroacetimidate, generally requires a $\mathrm{p} K_{\mathrm{a}}$ value less than 5 for activation at room temperature [32-36]. It is known from the literature that pyridinium salts exhibit $\mathrm{p} K_{\mathrm{a}}$ values of about 5.2 [37] Of late, Berkessel et al. disclosed an elegant method, where different electron deficient pyridinium salts (expected $\mathrm{p} K_{\mathrm{a}}$ values less than 5) were used as a catalyst for the activation of glycals to provide stereoselective 2-deoxyglycosides with high yields [38]. Based on this fact, we anticipated that for electron-deficient pyridinium salts the $\mathrm{p} K_{\mathrm{a}}$ value would be further diminished in the presence of hydrogen-bonding cocatalysts such as thiourea derivatives. The presence of Schreiner's thiourea in the reaction medium enhances the acidity of the ammonium salt due to doubling their dual hydrogen bonding ability with the carboxylate and the alkoxy group of the ammonium salt. A thiourea derivative also enhances the nucleophilicity of the glycosyl acceptor by imparting a partial negative charge on it. Hence, the application of the synergistic catalyst system consisting of electron-deficient pyridinium salts/thiourea derivatives for glycosidic bond formation will be an exciting addition to the literature (Scheme 1).

\section{Results and Discussion}

To check our hypothesis, a series of ${ }^{1} \mathrm{H}$ NMR spectroscopic studies were conducted by selecting commonly used $O$-glucopyranosyl trichloroacetimidate $\mathbf{1} \boldsymbol{\alpha}$ [39-41] as glycosyl donor and 3,5-di(methoxycarbonyl)- $N$-(cyanomethyl)pyridinium bromide (3a) as a catalyst. For example, when glycosyl donor $\mathbf{1} \alpha$ was treated with catalyst $\mathbf{3 a}(10 \mathrm{~mol} \%)$ at room temperature for $4 \mathrm{~h}$ (Table 1, entry 1 ) in $\mathrm{CD}_{2} \mathrm{Cl}_{2}$ solvent, it was observed that there is neither any interaction of $\mathbf{1} \alpha$ with catalyst $\mathbf{3 a}$ nor decomposition of $\mathbf{1 \alpha}$ (Figure $1 \mathrm{~b}$ ) as the peak position of $\mathbf{1 \alpha}$ remained unchanged. The salt remains insoluble in $\mathrm{CD}_{2} \mathrm{Cl}_{2}$ and hence did not show any peak in the ${ }^{1} \mathrm{H}$ NMR spectra. However, when the mixture of electron-deficient pyridinium salt 3a and glycosyl acceptor 2a (1:1) was dissolved in $\mathrm{CD}_{2} \mathrm{Cl}_{2}$ and investigated by ${ }^{1} \mathrm{H} \mathrm{NMR}$, an upfield shift of the $-\mathrm{CH}_{2}$ - peak of 3a from $\delta 6.17$ to $\delta 4.03$ (Figure 2c) was observed. This result clearly supports the possible formation of 1,2 -adduct $\mathbf{X}$, on the reaction of $\mathbf{3 a}$ with $\mathbf{2 a}$ which is eventually responsible for the loss of aromaticity of the pyridinium ring.

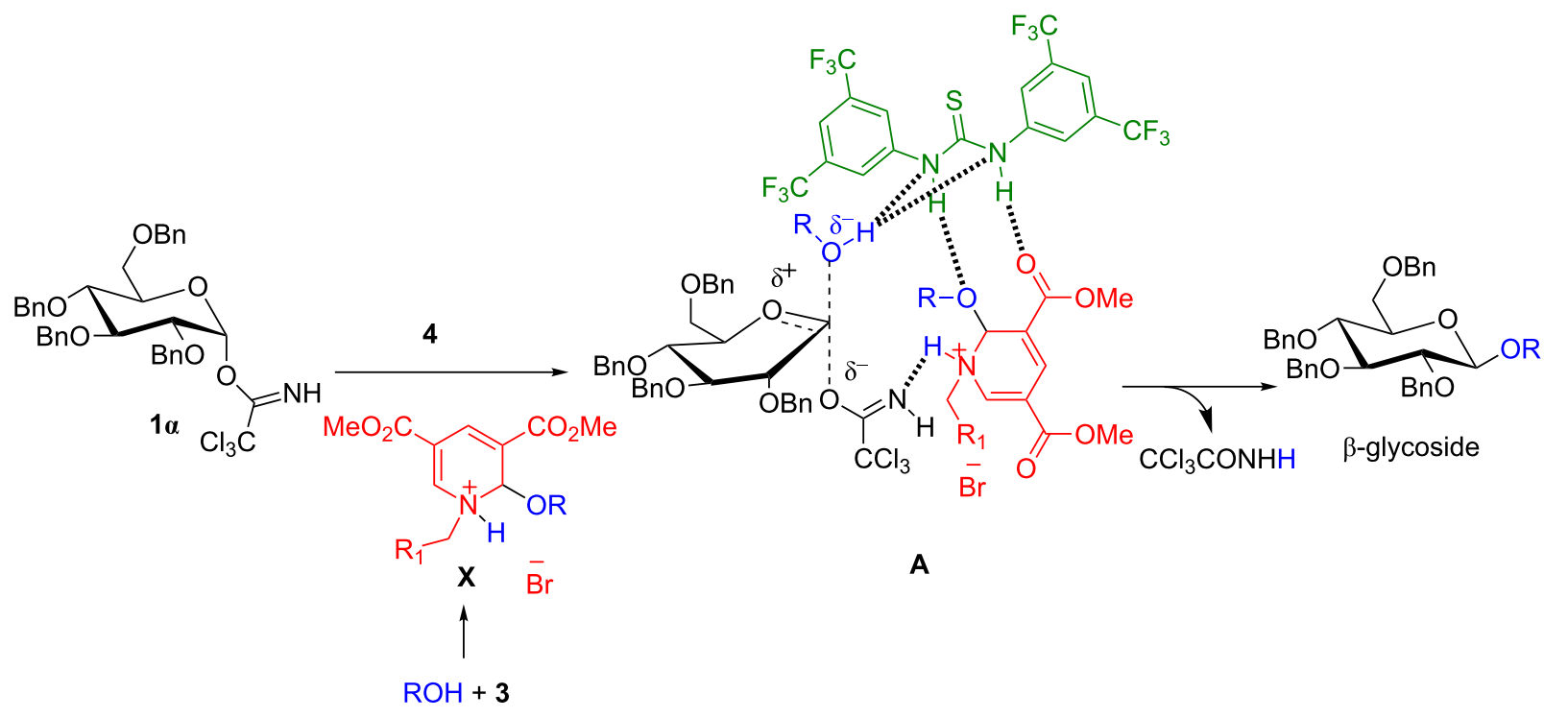


Table 1: Optimization of reaction conditions ${ }^{a}$

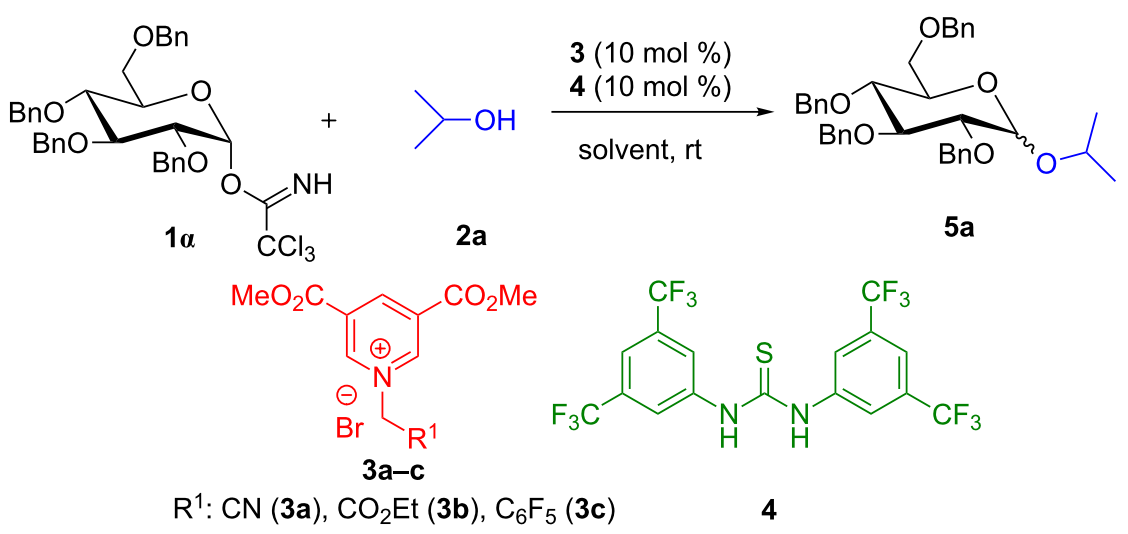

\begin{tabular}{|c|c|c|c|c|c|}
\hline entry & catalyst & cocatalyst 4 & solvent & reaction time & yield $^{b}\left(\alpha / \beta\right.$ ratio $\left.^{c}\right)$ \\
\hline $1^{d}$ & $3 a$ & - & $\mathrm{DCM}$ & $4 \mathrm{~h}$ & n.r., n.d. ${ }^{e}$ \\
\hline 2 & $3 a$ & - & DCM & $24 \mathrm{~h}$ & $56 \%(1: 1)^{f}$ \\
\hline $3^{g}$ & $3 a$ & - & DCM & $4 \mathrm{~h}$ & $86 \%(1.1: 1)$ \\
\hline 4 & $3 a$ & + & DCM & $2 \mathrm{~h}$ & $90 \%(2.2: 1)$ \\
\hline 5 & $3 b$ & + & $\mathrm{DCM}$ & $6 \mathrm{~h}$ & $72 \%(2: 1)$ \\
\hline 6 & $3 c$ & + & DCM & $8 \mathrm{~h}$ & $64 \%(1.7: 1)$ \\
\hline $7^{\mathrm{h}}$ & $3 a$ & + & DCM & $5 \mathrm{~h}$ & $86 \%(2.1: 1)$ \\
\hline 8 & $3 a$ & + & $\mathrm{ACN}$ & $4 \mathrm{~h}$ & $56 \%(2.1: 1)$ \\
\hline 9 & $3 a$ & + & THF & $7 \mathrm{~h}$ & $37 \%(1: 1)$ \\
\hline 10 & $3 a$ & + & toluene & $24 \mathrm{~h}$ & trace \\
\hline 11 & $3 a$ & + & DCE & $3 \mathrm{~h}$ & $80 \%(1.4: 1)$ \\
\hline $12^{i}$ & $3 a$ & + & $\mathrm{DCM}$ & $5 \mathrm{~h}$ & $82 \%(2: 1)$ \\
\hline 13 & $\mathrm{HBr}$ & - & $\mathrm{DCM}$ & $8 \mathrm{~h}$ & trace $^{j}$ \\
\hline $14^{\mathrm{k}}$ & $3 a$ & - & DCM & $4 \mathrm{~h}$ & n.r. \\
\hline
\end{tabular}

aReaction conditions: $1 \alpha(0.15 \mathrm{mmol}), \mathbf{2 a}(0.165 \mathrm{mmol}), 3 a-c(10 \mathrm{~mol} \%), \mathbf{4}(10 \mathrm{~mol} \%)$, solvent $(3 \mathrm{~mL})$, at room temperature under nitrogen atmosphere. bYield of isolated product. ${ }^{c}$ Anomeric ratios were determined by ${ }^{1} \mathrm{H}$ NMR spectroscopy. ${ }^{\mathrm{d}} \mathbf{1 \alpha}$ was stirred with $10 \mathrm{~mol} \% \mathbf{3 a}$ for $4 \mathrm{~h}$ at room temperature. ${ }^{\mathrm{e}}$ n.r. - no reaction, n.d. - no decomposition. ${ }^{f}$ Reaction was not completed. ${ }^{9} 25 \mathrm{~mol} \%$ of 3 a was used. hPerformed at $0{ }^{\circ} \mathrm{C}$. I'Inverse addition condition. ${ }^{j}$ A trace amount of glucosyl bromide was also formed. ${ }^{2} 25 \mathrm{~mol} \%$ of 2,4,6-trimethylpyridine was added.

Based on the outcomes of ${ }^{1} \mathrm{H}$ NMR spectroscopic studies, we started optimizing the reaction conditions. Upon treatment of glycosyl donor $\mathbf{1} \boldsymbol{\alpha}$ and glycosyl acceptor $\mathbf{2 a}$ in 1:1.1 molar ratio with $10 \mathrm{~mol} \%$ of 3a in dry DCM at room temperature, the desired $O$-glycoside 5 a was isolated in $56 \%$ yield and with poor selectivity (Table 1, entry 2). The use of $25 \mathrm{~mol} \%$ of $\mathbf{3 a}$ was required to drive the reaction to completion with $86 \%$ yield (Table 1, entry 3). This result, as envisaged, was indeed interesting and encouraging, which clearly indicates the ability of the electron-deficient pyridinium salt to activate the trichloroacetimidate donor. However, it took longer reaction time and required higher catalyst loading (up to $25 \mathrm{~mol} \%$ ). This outcome can be attributed to lower acidity of the ammonium salt formed by 1,2 -addition of the acceptor to the pyridinium salt. The conjugate base formed after the release of a proton from the ammonium salt may be quite stable to impart a negative charge to the acceptor oxygen.
The acidity of the ammonium salt may be enhanced by the introduction of a cocatalyst such as an aryl thiourea derivative, which has the ability to form a dual hydrogen bond with the carboxylate and the alkoxy group of the ammonium salt [4244]. To ensure our postulation, a ${ }^{1} \mathrm{H}$ NMR spectroscopic study was carried out with a mixture of glycosyl acceptor $\mathbf{2 a}$, pyridinium salt 3a (10 $\mathrm{mol} \%)$ and aryl thiourea 4 (10 mol \%) in $\mathrm{CD}_{2} \mathrm{Cl}_{2}$ at room temperature (Figure 3). The -Me peak of $-\mathrm{CO}_{2} \mathrm{Me}$ of the ammonium salt shifted from $\delta 4.09$ to $\delta 3.97$, which indirectly confirms the presence of hydrogen bonding between - $\mathrm{NH}$ of the thiourea and the carbonyl carbon of $-\mathrm{CO}_{2} \mathrm{Me}$ of 3a (Figure 3d). Also, the magnification of the nucleophilicity of the glycosyl acceptor by the thiourea derivative results in shifting of the $-\mathrm{OH}$ peak from $\delta 2.70$ to $\delta 3.62$ (Figure 3d).

Once this understanding was gained from ${ }^{1} \mathrm{H}$ NMR studies, aryl thiourea cocatalyst $4(10 \mathrm{~mol} \%)$ was added with $10 \mathrm{~mol} \%$ of 


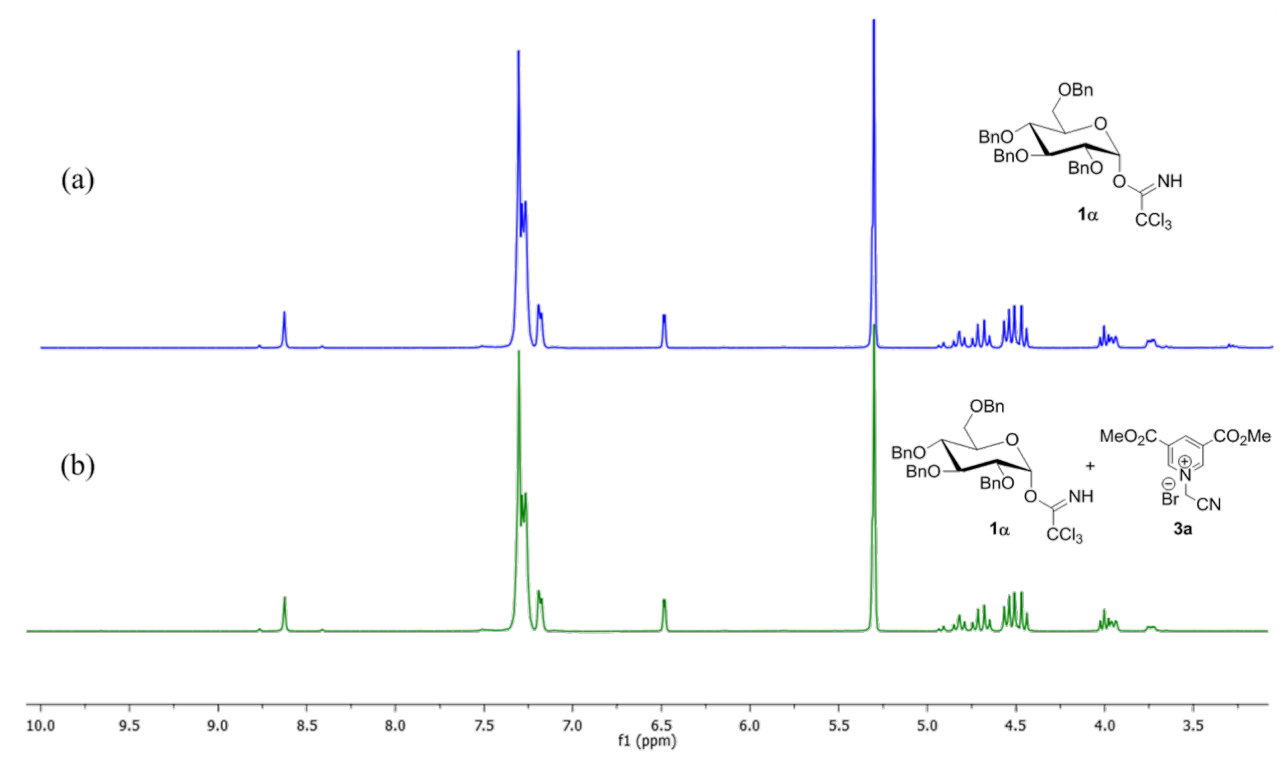

Figure 1: ${ }^{1} \mathrm{H}$ NMR (a) glycosyl donor $1 \alpha$ and $(b)$ a mixture of $1 \alpha$ and $10 \mathrm{~mol} \% 3 a$ in $\mathrm{CD}_{2} \mathrm{Cl}_{2}$ at room temperature.

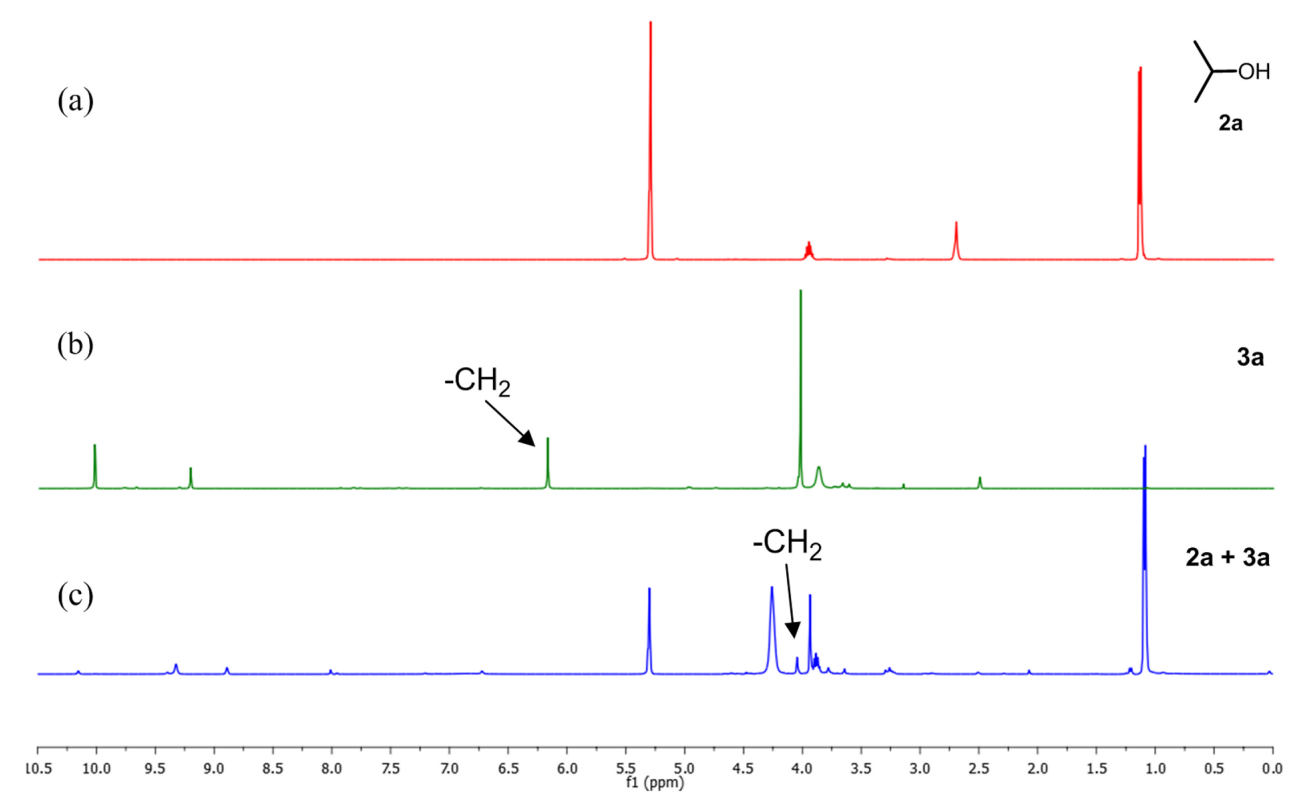

Figure 2: ${ }^{1} \mathrm{H}$ NMR (a) glycosyl acceptor $\mathbf{2 a}$, (b) pyridinium salt $\mathbf{3} \mathbf{a}$ (in DMSO- $d_{6}$ ) and (c) a mixture of $\mathbf{2 a}$ and $\mathbf{3} \mathbf{a}$ in $1: 1$ ratio in $\mathrm{CD}_{2} \mathrm{Cl}_{2}$ at room temperature.

3a to the reaction mixture of $\mathbf{1} \boldsymbol{\alpha}$ and $\mathbf{2 a}$ and pleasingly the reaction was completed within a short span of time, glycoside 5a was obtained with improved yield $(90 \%)$ and selectivity $(\alpha: \beta$ 2.2:1 ratio, Table 1, entry 4). Furthermore, several other catalysts were also screened for glycosylation, such as 3,5di(methoxycarbonyl)- $N$-[(ethoxycarbonyl)methyl]pyridinium bromide (3b, Table 1, entry 5), 3,5-di(methoxycarbonyl)- $N$ - [(pentafluorophenyl)methyl]pyridinium bromide (3c, Table 1, entry 6). However, the results were not up to our expectation and the desired glycoside was obtained in low yield. Once, we fixed the catalyst for glycosylation, further parameters were also optimized. Lowering the reaction temperature (room temperature to $0{ }^{\circ} \mathrm{C}$ ), the product formation rate slowed down and the selectivity remains unchanged (Table 1 , entry 7 ). Similarly, 


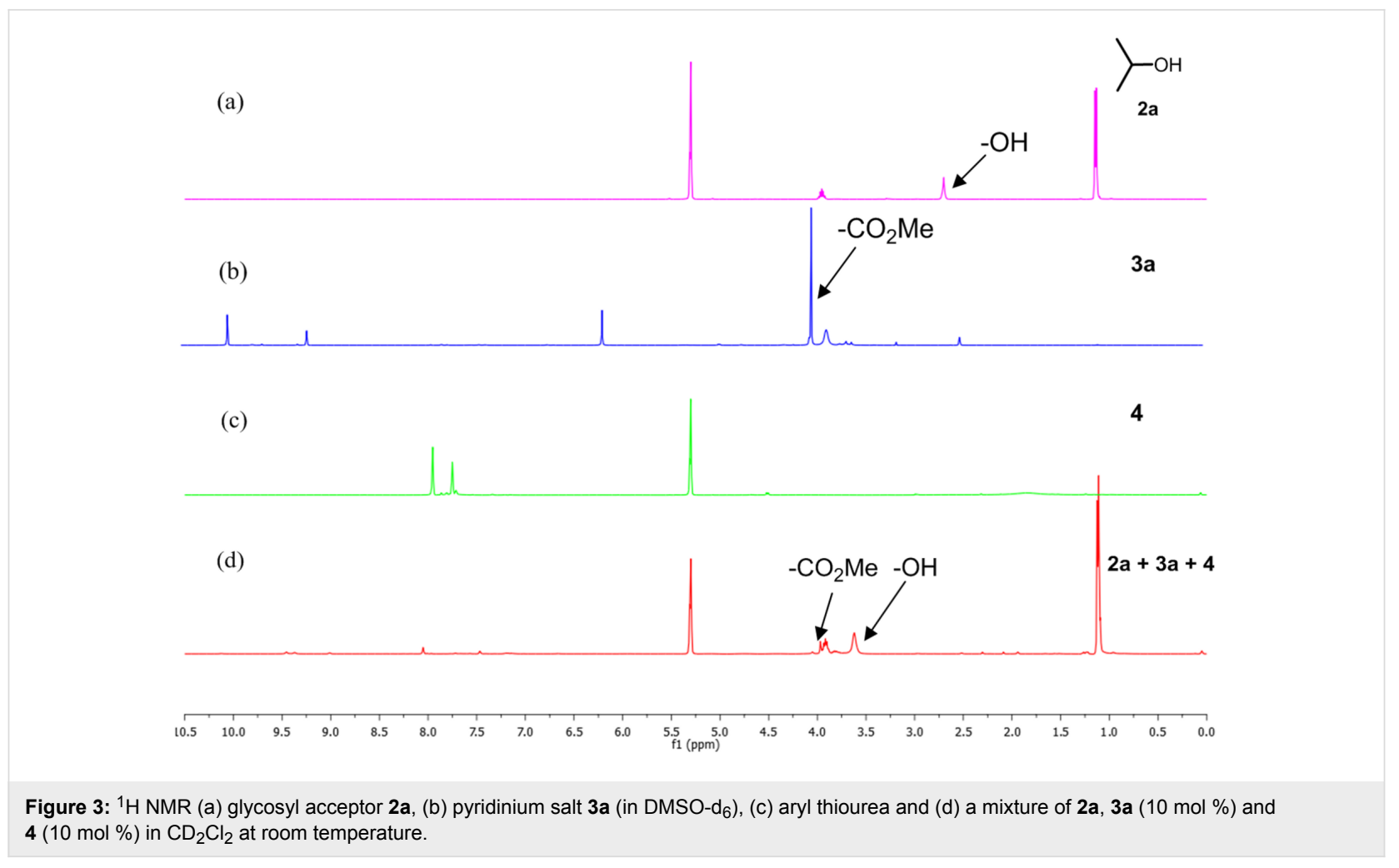

changing the solvent system to acetonitrile, tetrahydrofuran, toluene, and dichloroethane had an adverse effect on the reaction rate, yield and selectivity (Table 1, entries 8-11). Performing the reaction under inverse addition conditions had no impact on the selectivity of glycoside formation (Table 1, entry 12) $[39,40]$. Aware of the fact that $\mathrm{HBr}$, which is eventually generated in situ during the course of reaction from ammonium salt $\mathbf{X}$, might be the potential catalyst for the activation of the glycosyl trichloroacetimidate donor, we conducted an additional experiment. Glycosyl donor $\mathbf{1} \alpha$ was treated with $25 \mathrm{~mol} \%$ of $\mathrm{HBr}$ instead of pyridinium salt 3a (Table 1, entry 13) where only a trace of glycoside 5a and some glycosyl bromide were formed along with the hydrolyzed product. Hence, it could be concluded that $\mathrm{HBr}$ is not the real catalyst in this cooperative catalysis. Further, the addition of acid scavenger such as 2,4,6trimethylpyridine inhibits the formation of the glycoside, which indirectly supports that the pyridinium salt is a decisive catalyst for the activation of the glycosyl trichloroacetimidate donor (Table 1, entry 14). Therefore, the optimal reaction conditions for $O$-glycosylation are the following: the use of 3,5di(methoxycarbonyl)- $N$-(cyanomethyl)pyridinium bromide (3a) as catalyst (10 mol \%), thiourea derivative 4 as cocatalyst (10 mol \%) and dichloromethane as solvent at room temperature (Table 1, entry 4).

With the optimized conditions in hand, our emphasis was then focused on the exploration of the synergistic catalytic system on glycosylation of $\mathbf{1} \boldsymbol{\alpha}$ with several acceptors (Table 2). In all cases, reactions proceeded smoothly within $2-6 \mathrm{~h}$ and in good yields with moderate to good selectivity, as determined by the ${ }^{1} \mathrm{H}$ and ${ }^{13} \mathrm{C}$ NMR spectra. Glycosylation with less sterically hindered primary alcohols, e.g., allyl alcohol (2b), benzyl alcohol (2c), 4-methoxy benzyl alcohol (2d), and secondary alcohols, e.g., cyclohexanol (2e), cyclopentanol (2f) produced their corresponding glucosides $\mathbf{5 b}-\mathbf{f}$ in $78-88 \%$ yields and with moderate $\alpha$-selectivity (Table 2 , entries $1-5$ ). It is important to note that, when a halogenated primary alcohol such as 2-bromoethanol $(\mathbf{2 g})$ was treated with glycosyl donor $\mathbf{1} \alpha$, it gave exclusively $\beta$-glycoside $\mathbf{5 g}$ in $72 \%$ yield (Table 2 , entry 6 ). However, 3-chloropropanol (2h) as acceptor procured glucoside $\mathbf{5 h}$ in $70 \%$ yield with marginal selectivity (Table 2 , entry 7). Similarly, the reaction with the bulky primary alcohol, 1-adamantanemethanol (2i) produced the desired glucoside $\mathbf{5 i}$ in $75 \%$ yield and moderate selectivity (Table 2, entry 8 ). Further, reactions with hindered acceptors, for instance, 1-adamantanol (2j), (+)-menthol (2k), (-)-menthol (2l), cholesterol (2m) required longer reaction times with high catalyst loading and produced the desired glucosides $\mathbf{5 j} \mathbf{j}-\mathbf{m}$, respectively, in moderate to good yields (43-67\%) and with good $\alpha$-selectivity (Table 2, entries 9-12). As expected, on treatment with a sugar-based acceptor such as 1,2:3,4-di- $O$-isopropylidene-D-galactose (2n), the corresponding glycoside $\mathbf{5 n}$ was produced in $72 \%$ yield with moderate selectivity (Table 2, entry 13) and the acid sensitive group survived well [34]. 
Table 2: Acceptor scope in glycosylation reaction with donor $1 \alpha^{\mathrm{a}}$.

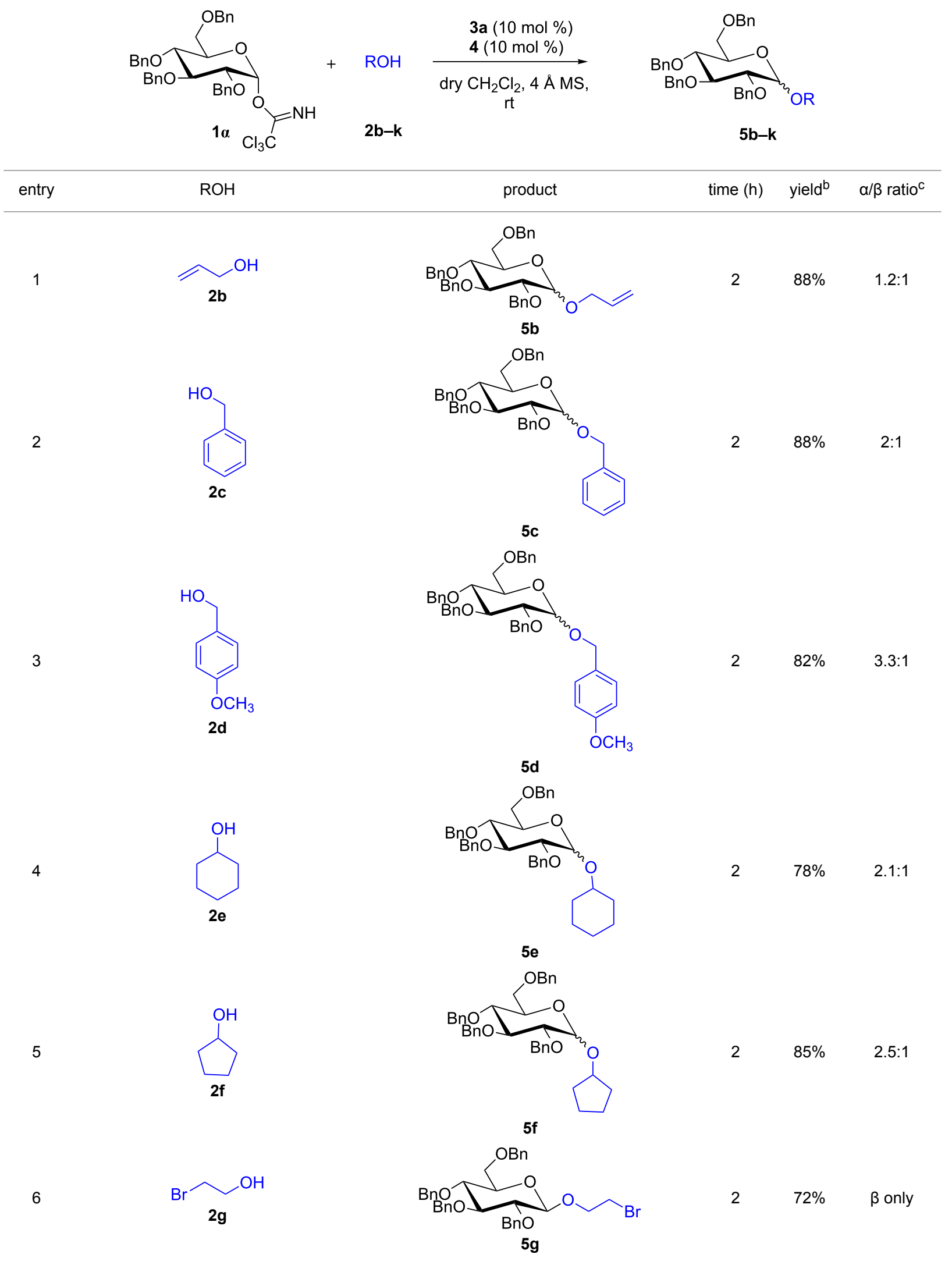


Table 2: Acceptor scope in glycosylation reaction with donor $1 \mathbf{a}^{\mathrm{a}}$. (continued)<smiles>OCCCCl</smiles>

$2 \mathrm{~h}$<smiles>OCC12CC3CC(CC(C3)C1)C2</smiles>

2i

$9^{d}$<smiles>OC12CC3CC(CC(C3)C1)C2</smiles>

2j

$10^{d}$<smiles>[Z10]C(C)[C@H]1CC[C@@H](C)C[C@H]1O</smiles>

$11^{d}$<smiles>[C]C(C)[C@H]1CC[C@@H](C)C[C@H]1O</smiles>

$12^{d}$<smiles>CC(C)CCC[C@H](C)[C@H]1CCC2[C@@H]3CC=C4C[C@@H](O)CC[C@]4(C)[C@H]3CC[C@]21C</smiles>

$2 \mathrm{~m}$

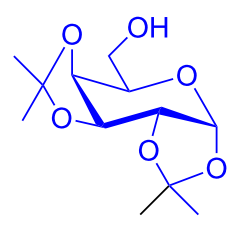

2n

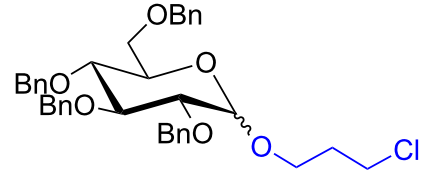

$5 \mathrm{~h}$

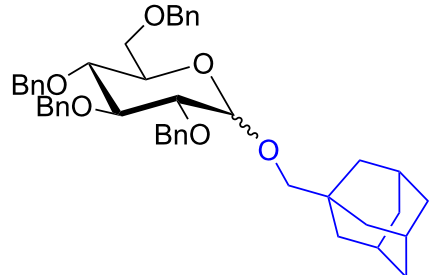

$5 i$

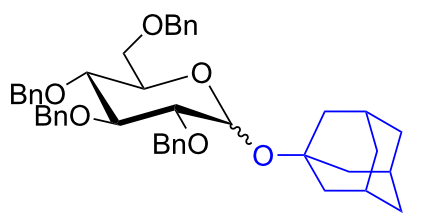

5j

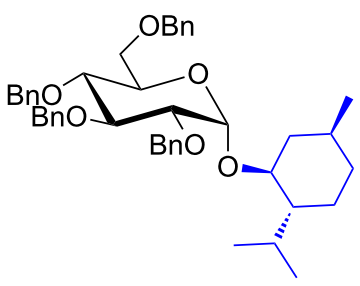

5k

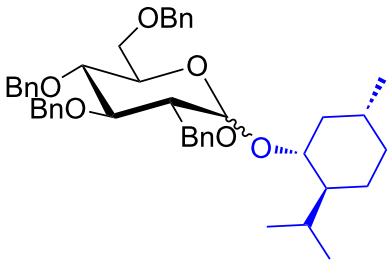

5I

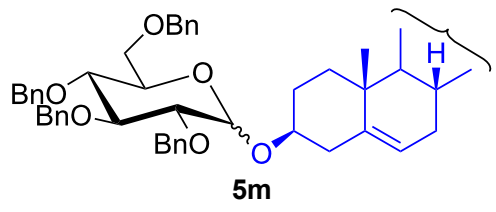

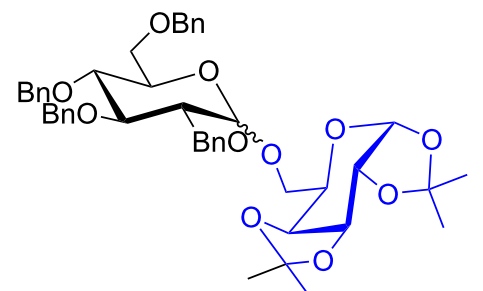

6 $60 \%$

$2 \quad 70 \% \quad 1.1: 1$

$6 \quad 75 \% \quad 3.3: 1$

$5 \quad 43 \% \quad 2: 1$

$4 \quad 61 \% \quad$ a only

$4 \quad 67 \% \quad 5: 1$

$3 \quad 72 \% \quad 1: 1.3$

aReaction conditions: $\mathbf{1} \alpha(0.15 \mathrm{mmol}), \mathbf{2 a}-\mathbf{n}(0.165 \mathrm{mmol}), \mathbf{3 a}(10 \mathrm{~mol} \%), \mathbf{4}(10 \mathrm{~mol} \%)$, solvent $(3 \mathrm{~mL})$, at room temperature under nitrogen atmosphere. ${ }^{b}$ Yield of isolated product. ${ }^{\mathrm{C}}$ Anomeric ratios were determined by ${ }^{1} \mathrm{H}$ NMR spectroscopy. ${ }^{\mathrm{d}} 20 \mathrm{~mol} \%$ of $3 \mathrm{a}$ and 20 mol \% of 4 was used. 
To further demonstrate the efficacy of this method other important glycosides were synthesized with different donors as tabulated in Table 3. Glycosylation of D-galactopyranosyl trichloroacetimidate $\mathbf{6} \boldsymbol{\alpha}$ with a variety of glycosyl acceptors, e.g., $\mathbf{2 c}, \mathbf{2 g}$, $\mathbf{2 h}, \mathbf{2 i}$ and $\mathbf{2 n}$ under the optimized reaction conditions gave their corresponding galactosides 9-13, respectively, with moderate selectivity (Table 3, entry 1-5) [40,41]. Similarly, the reaction of D-mannopyranosyl trichloroacetimidate $\mathbf{7} \boldsymbol{\alpha}$ with glycosyl acceptors $2 \mathbf{c}, \mathbf{2 g}, \mathbf{2 h}$, and $\mathbf{2 n}$ produces their corresponding mannosides 14-18 (61-78\% yields) with moderate selectivity (Table 3, entries 6-10) [40,41]. Gratifyingly, the highest stereoselective outcome was observed when 4,6-O-benzylidine-2,3di- $O$-benzyl- $\alpha$-D-glucopyranosyl trichloroacetimidate $\mathbf{8} \boldsymbol{\alpha}$ was used as a glycosyl donor. For example, when $\mathbf{8 \alpha}$ was treated with different donors such as $\mathbf{2 i}, \mathbf{2} \mathbf{m}, \mathbf{2 n}$ under the optimized conditions, glucosides 19-21 were procured in good yields with excellent $\alpha$-selectivity (Table 3, entry 11-13) [45].

The regioselective glycosylation is an important aspect in carbohydrate chemistry. It is pleasing to note that on reaction with partially protected acceptor $\mathbf{2 2}$ with glycosyl donors $\mathbf{1 \alpha}$ and $7 \boldsymbol{\alpha}$ under the optimized conditions lead to the regioisomeric products 23 and 24 [46,47] in moderate yields with good selectivity (Scheme 2).

\section{Plausible mechanism}

To confirm the reaction pathway, few additional control experiments were carried out (for details see Supporting Information File 1). When the reaction was performed with 1.0 equiv of $\mathbf{3 a}$ and acceptor 2a under standard inverse procedure conditions, the desired $O$-glycoside 5a was procured in 36\% yield and $56 \%$ of $1 \alpha$ was recovered through column chromatography. Therefore, we conclude that the reaction would have followed an intermolecular glycosylation reaction through an oxocarbenium ion. Combining all of these observations and results from earlier literature reports, a plausible reaction mechanism for the electron-deficient pyridinium salt/thiourea cocatalyzed glycosidation is outlined in Figure 4. It is presumed that at first electrondeficient pyridinium salt 3a undergoes 1,2-addition with the acceptor to produce ammonium salt $\mathbf{X}$. The addition of the thiourea derivative as hydrogen-bonding cocatalyst could activate the glycosyl donor by increasing the acidity of ammonium salt

Table 3: Glycosylation of donors $6 \alpha-8 \alpha$ with variety of acceptors ${ }^{a}$
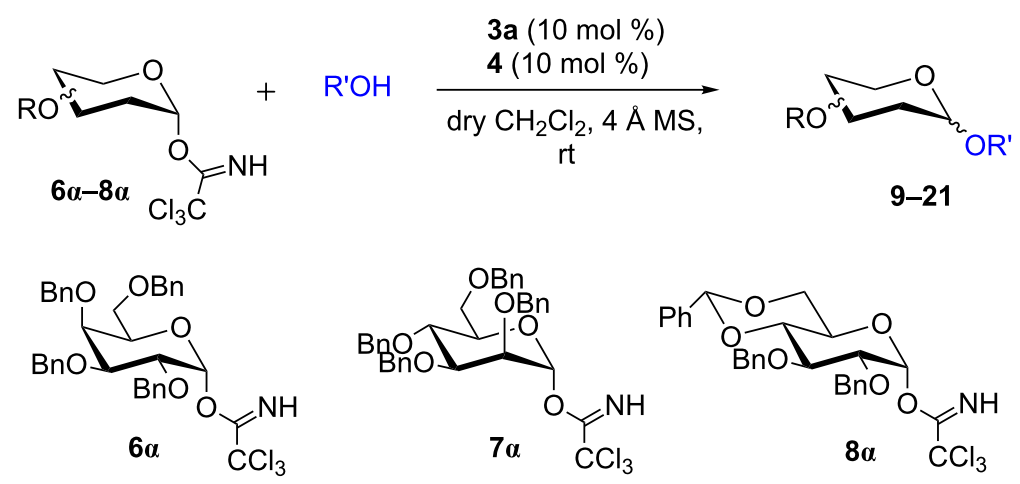

\begin{tabular}{|c|c|c|c|c|c|c|}
\hline entry & donor & acceptor & product & time $(\mathrm{h})$ & yield $^{b}$ & $\alpha / \beta$ ratio $^{c}$ \\
\hline 1 & $6 \alpha$ & $2 c$ & 9 & 2 & $91 \%$ & $1.7: 1$ \\
\hline 2 & & $2 g$ & 10 & 2 & $74 \%$ & $2.1: 1$ \\
\hline 3 & & $2 \mathrm{~h}$ & 11 & 2 & $81 \%$ & $1: 4.6$ \\
\hline 4 & & $2 i$ & 12 & 6 & $73 \%$ & $2.6: 1$ \\
\hline 5 & & $2 n$ & 13 & 3 & $62 \%$ & $1.4: 1$ \\
\hline 6 & $7 \alpha$ & $2 c$ & 14 & 2 & $74 \%$ & $1.2: 1$ \\
\hline 7 & & $2 g$ & 15 & 2 & $78 \%$ & $3: 1$ \\
\hline 8 & & $2 \mathrm{~h}$ & 16 & 2 & $77 \%$ & 1.9:1 \\
\hline $9^{d}$ & & $2 \mathrm{~m}$ & 17 & 7 & $68 \%$ & $1: 1.9$ \\
\hline 10 & & $2 n$ & 18 & 3 & $61 \%$ & $\alpha$ only \\
\hline 11 & $8 \alpha$ & $2 i$ & 19 & 6 & $61 \%$ & $\alpha$ only \\
\hline $12^{d}$ & & $2 m$ & 20 & 8 & $54 \%$ & $\alpha$ only \\
\hline 13 & & $2 n$ & 21 & 4 & $61 \%$ & $\alpha$ only \\
\hline
\end{tabular}

aReaction conditions: donor $(0.15 \mathrm{mmol})$, acceptor $(0.165 \mathrm{mmol}), \mathbf{3 a}(10 \mathrm{~mol} \%), 4(10 \mathrm{~mol} \%)$, solvent $(3 \mathrm{~mL})$, at room temperature under nitrogen at-

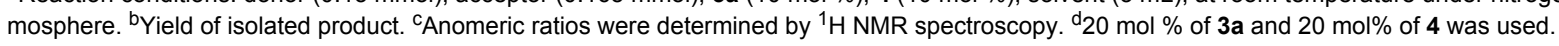




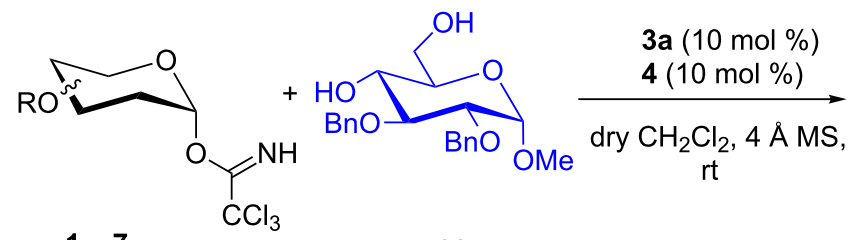

$1 \alpha, 7 \alpha$
22

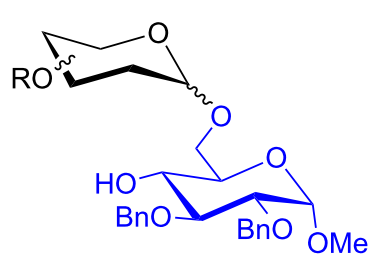

23,24

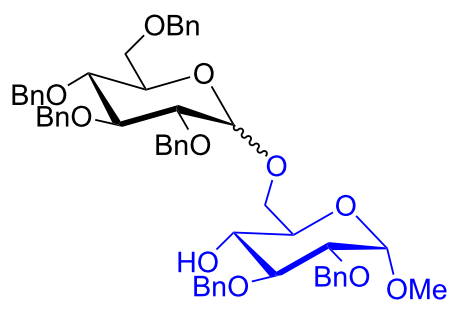

23

12 h, $62 \%, 3.2: 1$

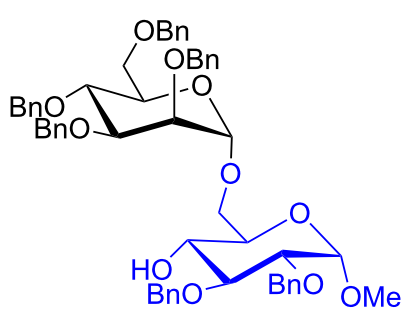

24

12 h, $63 \%, \alpha$ only

Scheme 2: Synergistic electron-deficient pyridinium salt/aryl thiourea-catalyzed regioselective O-glycosylation.

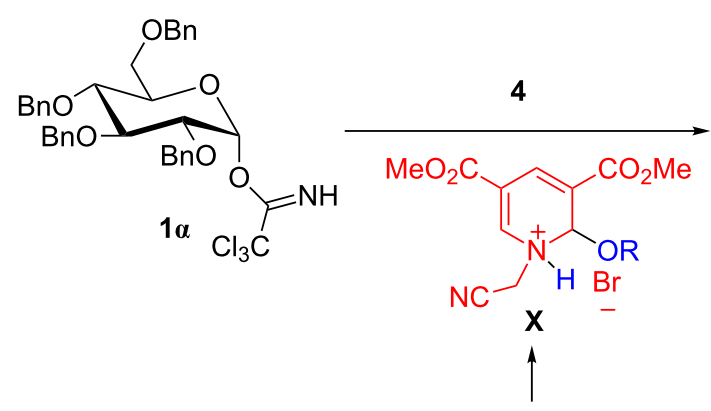

$\mathrm{ROH}+\mathbf{3 a}$

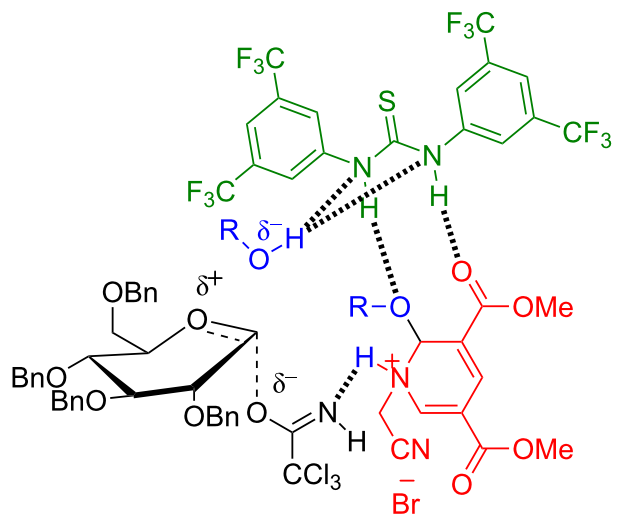

A

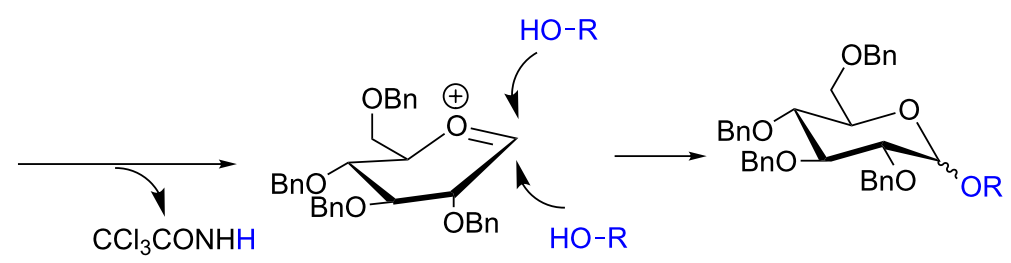

B

$5 \alpha, \beta$

Figure 4: Plausible reaction mechanism.

$\mathbf{X}$ to form an oxocarbenium intermediate B. Further, the nucleophilic attack of the acceptor to the oxocarbenium ion $\mathbf{B}$ would produce the desired glycoside $\mathbf{5}$. Higher $\alpha$-selectivity may be attributed to the anomeric effect.

\section{Conclusion}

In conclusion, we have disclosed an efficient and general protocol for the glycosylation of trichloroacetimidate glycosyl donors using the concept of cooperativity between an electron- 
deficient pyridinium salt and an aryl thiourea derivative. ${ }^{1} \mathrm{H}$ NMR studies divulge that a 1,2-adduct formation between the electron-deficient pyridinium salt and the glycosyl acceptor plays a crucial role for the activation of the trichloroacetimidate donors. The presence of thiourea derivatives further enhances the reaction rate and selectivity due to its dual hydrogen bonding ability. The reaction proceeds smoothly at room temperature with good to excellent yields and $\alpha$-selectivity and is applicable to a wide range of glycosyl donors as well as acceptors. The advantage of this methodology lies in the usage of an environmentally benign catalyst, mild reaction conditions and the regioselective formation of $O$-glycosides.

\section{Supporting Information}

\section{Supporting Information File 1}

Experimental procedures and analytical data.

[http://www.beilstein-journals.org/bjoc/content/

supplementary/1860-5397-13-236-S1.pdf]

\section{Acknowledgements}

This work was supported by SERB New Delhi - SB/FT/CS069/2014 and the Indian Institute of Technology Patna. M.S. thanks IIT Patna for providing a research fellowship. The author acknowledges IIT Patna, BITS Pilani, SAIF-CDRI Lucknow for providing the analytical facility.

\section{ORCID ${ }^{\circledR}$ iDs}

Amit Kumar - https://orcid.org/0000-0002-1683-7740

\section{References}

1. Peng, P.; Schmidt, R. R. Acc. Chem. Res. 2017, 50, 1171-1183. doi:10.1021/acs.accounts.6b00518

2. Zhu, X.; Schmidt, R. R. Angew. Chem., Int. Ed. 2009, 48, 1900-1934. doi:10.1002/anie.200802036

3. Varki, A. Glycobiology 1993, 3, 97-130. doi:10.1093/glycob/3.2.97

4. Doores, K. J.; Gamblin, D. P.; Davis, B. G. Chem. - Eur. J. 2006, 12, 656-665. doi:10.1002/chem.200500557

5. Park, Y.; Harper, K. C.; Kuhl, N.; Kwan, E. E.; Liu, R. Y.; Jacobsen, E. N. Science 2017, 355, 162-166. doi:10.1126/science.aal1875

6. Seeberger, P. H. Acc. Chem. Res. 2015, 48, 1450-1463. doi:10.1021/ar5004362

7. Nigudkar, S. S.; Demchenko, A. V. Chem. Sci. 2015, 6, 2687-2704. doi:10.1039/C5SC00280J

8. Shaw, M.; Kumar, A.; Thakur, R. Trends Carbohydr. Res. 2017, 9, $1-28$.

9. Toshima, K.; Tatsuta, K. Chem. Rev. 1993, 93, 1503-1531. doi:10.1021/cr00020a006

10. Davis, B. G. J. Chem. Soc., Perkin Trans. 1 2000, 2137-2160. doi:10.1039/A809774G

11. Crout, D. H. G.; Vic, G. Curr. Opin. Chem. Biol. 1998, 2, 98-111. doi:10.1016/S1367-5931(98)80041-0
12. Withers, S. G. Carbohydr. Polym. 2001, 44, 325-337. doi:10.1016/S0144-8617(00)00249-6

13. Lopez, X.; Mujika, J. I.; Blackburn, G. M.; Karplus, M. J. Phys. Chem. A 2003, 107, 2304-2315. doi:10.1021/jp022014s

14. MacMillan, D. W. C. Nature 2008, 455, 304-308. doi:10.1038/nature07367

15. Gröger, H.; Wilken, J. Angew. Chem., Int. Ed. 2001, 40, 529-532. doi:10.1002/1521-3773(20010202)40:3<529::AID-ANIE529>3.0.CO;2$\mathrm{X}$

16. Balmond, E. I.; Galan, M. C.; McGarrigle, E. M. Synlett 2013, 2335-2339. doi:10.1055/s-0033-1338970

17. Vedachalam, S.; Tan, S. M.; Teo, H. P.; Cai, S.; Liu, X.-W. Org. Lett. 2012, 14, 174-177. doi:10.1021/ol202959y

18. Berkessel, A.; Groeger, H. Asymmetric Organocatalysis: from Biomimetic Concepts to Applications in Asymmetric Synthesis; Wiley-VCH, 2005.

ISBN: 978-3-527-30517-9.

19. Chauhan, P.; Mahajan, S.; Kaya, U.; Hack, D.; Enders, D. Adv. Synth. Catal. 2015, 357, 253-281. doi:10.1002/adsc.201401003

20. Tu, Y.; Wang, Z.-X.; Shi, Y. J. Am. Chem. Soc. 1996, 118, 9806-9807. doi:10.1021/ja962345g

21. Sigman, M. S.; Jacobsen, E. N. J. Am. Chem. Soc. 1998, 120, 4901-4902. doi:10.1021/ja980139y

22. Corey, E. J.; Grogan, M. J. Org. Lett. 1999, 1, 157-160. doi:10.1021/ol990623।

23. Raup, D. E. A.; Cardinal-David, B.; Holte, D.; Scheidt, K. A. Nat. Chem. 2010, 2, 766-771. doi:10.1038/nchem.727

24. Weil, T.; Kotke, M.; Kleiner, C. M.; Schreiner, P. R. Org. Lett. 2008, 10, 1513-1516. doi:10.1021/ol800149y

25. Zhang, Z.; Schreiner, P. R. Chem. Soc. Rev. 2009, 38, 1187-1198. doi:10.1039/B801793J

26. Zhang, Z.; Lippert, K. M.; Hausmann, H.; Kotke, M.; Schreiner, P. R. J. Org. Chem. 2011, 76, 9764-9776. doi:10.1021/jo201864e

27. Klausen, R. S.; Jacobsen, E. N. Org. Lett. 2009, 11, 887-890. doi:10.1021/ol802887h

28. Uraguchi, D.; Ueki, Y.; Ooi, T. Science 2009, 326, 120-123. doi:10.1126/science.1176758

29. Hong, L.; Sun, W.; Yang, D.; Li, G.; Wang, R. Chem. Rev. 2016, 116, 4006-4123. doi:10.1021/acs.chemrev.5b00676

30. Geng, Y.; Kumar, A.; Faidallah, H. M.; Albar, H. A.; Mhkalid, I. A.; Schmidt, R. R. Angew. Chem., Int. Ed. 2013, 52, 10089-10092. doi:10.1002/anie.201302158

31. Palo-Nieto, C.; Sau, A.; Williams, R.; Galan, M. C. J. Org. Chem. 2017, 82, 407-414. doi:10.1021/acs.joc.6b02498

32. Schmidt, R. R. Angew. Chem., Int. Ed. Engl. 1986, 25, 212-235. doi:10.1002/anie.198602121

33. Kimura, T.; Eto, T.; Takahashi, D.; Toshima, K. Org. Lett. 2016, 18, 3190-3193. doi:10.1021/acs.orglett.6b01404

34. Mensah, E. A.; Azzarelli, J. M.; Nguyen, H. M. J. Org. Chem. 2009, 74, 1650-1657. doi:10.1021/jo802468p

35. Roy, R.; Palanivel, A. K.; Mallick, A.; Vankar, Y. D. Eur. J. Org. Chem. 2015, 4000-4005. doi:10.1002/ejoc.201500137

36. Kumar, A.; Kumar, V.; Dere, R. T.; Schmidt, R. R. Org. Lett. 2011, 13, 3612-3615. doi:10.1021/ol201231v

37. Portenkirchner, E.; Enengl, C.; Enengl, S.; Hinterberger, G.; Schlager, S.; Apaydin, D.; Neugebauer, H.; Knör, G.; Sariciftci, N. S. ChemElectroChem 2014, 1, 1543-1548. doi:10.1002/celc.201402132

38. Das, S.; Pekel, D.; Neudörfl, J.-M.; Berkessel, A. Angew. Chem., Int. Ed. 2015, 54, 12479-12483. doi:10.1002/anie.201503156 
39. Schmidt, R. R.; Michel, J. Angew. Chem., Int. Ed. Engl. 1980, 19, 731-732. doi:10.1002/anie.198007311

40. Schmidt, R. R.; Kinzy, W. Adv. Carbohydr. Chem. Biochem. 1994, 50, 21-123. doi:10.1016/S0065-2318(08)60150-X

41. Schmidt, R. R.; Toepfer, A. Tetrahedron Lett. 1991, 32, 3353-3356. doi:10.1016/S0040-4039(00)92704-7

42. Fan, E.; Van Arman, S. A.; Kincaid, S.; Hamilton, A. D. J. Am. Chem. Soc. 1993, 115, 369-370. doi:10.1021/ja00054a066

43. Albert, J. S.; Hamilton, A. D. Tetrahedron Lett. 1993, 34, 7363-7366. doi:10.1016/S0040-4039(00)60126-0

44. Raposo, C.; Crego, M.; Mussons, M. L.; Caballero, M. C.; Morán, J. R. Tetrahedron Lett. 1994, 35, 3409-3410. doi:10.1016/S0040-4039(00)76921-8

45. Cancogni, D.; Lay, L. Synlett 2014, 25, 2873-2878. doi:10.1055/s-0034-1379471

46. Michigami, K.; Terauchi, M.; Hayashi, M. Synthesis 2013, 1519-1523. doi:10.1055/s-0033-1338469

47. Peng, P.; Schmidt, R. R. J. Am. Chem. Soc. 2015, 137, 12653-12659. doi:10.1021/jacs.5b07895

\section{License and Terms}

This is an Open Access article under the terms of the Creative Commons Attribution License (http://creativecommons.org/licenses/by/4.0), which permits unrestricted use, distribution, and reproduction in any medium, provided the original work is properly cited.

The license is subject to the Beilstein Journal of Organic Chemistry terms and conditions:

(http://www.beilstein-journals.org/bjoc)

The definitive version of this article is the electronic one which can be found at: doi:10.3762/bjoc. 13.236 